\title{
Optimal Public Subsidies of Nursing Home Insurance in the United States*
}

\author{
by Mark V. Pauly**
}

\section{Introduction}

All individuals, at any age, face a positive probability of illness and attendant medical expenses. In a non-trivial minority of illnesses, patients will experience a stay in a nursing home, an institution primarily providing custodial care to persons not fully well and unable to perform their normal functions. Sometimes nursing home stays are brief, representing a period of convalescence after an acute illness, and sometimes the stays are long term, the aftermath of an illness that becomes chronic, and continues until the person's death.

In the mixed public and private health care financing system in the U.S., many people are not initially eligible for public insurance for nursing home care. The incremental costs of nursing home care, over and above ordinary consumption expenses, are substantial. Recent estimates put the total cost of a year's nursing home stay of modest amenity at about $\$ 22,000$ per year (compared to average consumption expenses per elderly household of about $\$ 11,000$ per year), and costs can range as high as $\$ 100,000$ per year. An alternative to nursing home care is assistance in the home, but costs here are often as high as the incremental nursing home costs of about $\$ 10,000$ per year.

So individuals face large and unexpected nursing home expenses, yet purchase of private insurance coverage against such cost is quite rare, with only about two percent of the elderly purchasing coverage. Is such failure by presumably risk averse people to cover the cost of a low probability, high loss event another example of "irrational" behavior in the face of risk, or can non-purchase be squared with rational behavior? Whether private behavioral is rational or not, what is the appropriate form and basis (if any) for a public subsidy?

In this paper I will investigate one of the reasons for private non-purchase: The existence of the means-tested, publicly financed Medicaid program which pays for nursing home care once a person's wealth falls near to zero. (In other work (Pauly, [1988]), I have

\footnotetext{
* Invited paper.

** Professor of economics, University of Pennsylvania.
} 
discussed additional explanations for rational non-purchase.) I hasten to add that this is only a possible reason; to determine whether in reality people behave rationally or not will require empirical investigation.

In what follows I first show what is intuitively obvious, and has been argued by others: That the "wealth deductible" in current Medicaid discourages persons of low wealth from buying private coverage. Then I show that, perhaps surprisingly, this disincentive may well extend all the way up the distribution of wealth; it may help to explain why the moderately well-to-do fail to purchase insurance coverage, even if they rarely become eligible for public insurance. On a more positive note, I show that there exists an alternative public program, one which replaces Medicaid with a set of income or wealth-conditioned insurance subsidies, that is Pareto superior to Medicaid, and that does not redistribute expected income. For a given level of public spending, this arrangement can make all consumers better off.

Finally, I attempt to place the question of efficient subsidies in the broader framework of an explanation of why a society might subsidize long term care insurance. What normative economic goals might be achieved by such a system, and how might they efficiently be approached?

\section{The Medicaid program and the coverage of nursing home care}

Public payment for nursing home care is part of the broader U.S. Medicaid program to assist low income people in paying for their medical care costs. This program provides full insurance coverage against institutional care costs for individuals whose incomes and wealth fall below certain levels. Individuals can become eligible for coverage either by virtue of initial low levels of income and wealth, or because they "spend down" into eligibility, depleting their wealth to minimal levels and having only a moderate income available.

It is estimated that approximately 60 percent of Medicaid-covered nursing home beneficiaries become eligible by the spend-down route. Many of these people would have been classified as "middle class" before they entered a nursing home. Moreover, although nursing home care is not itself inordinately expensive, at about $\$ 50$ per day, including room and board, a stay of several months length can, by sheer force of longevity, wipe out the modest savings many individuals have. It is estimated that a nursing home stay of six months would deplete wealth enough to make an individual eligible for Medicaid for about 40 percent of today's elderly population.

There is very little private insurance purchased to protect against nursing home costs. While there is a flurry of development and marketing of private policies now going on, at most only about 2 percent of the elderly have private insurance coverage for a long stay. And even that coverage tends to be fairly limited in the amount it will pay per day and the time period it will cover. That is, even those who buy private coverage are not fully protected against eventual depletion of wealth; they too may eventually end up on Medicaid.

The consequence of this "safety net" public program, and the absence of private insurance, is that about half of all nursing home costs are paid by Medicaid. The other half is overwhelmingly paid privately out of pocket, without insurance coverage. 


\section{Medicaid and the incentive for private insurance coverage}

At an intuitive level, it is not hard to understand why low income/wealth elderly do not purchase private insurance coverage against nursing home costs. In all states the public Medicaid program provides nursing home coverage once a family's wealth falls below a certain level. Any private insurance benefits must be used before Medicaid will pay. It is easy to see that Medicaid, as a comprehensive insurance policy with a deductible equal to one's wealth, provides a close substitute, at a zero price, for private insurance coverage for low wealth people. What is more puzzling is why middle class elderly, who typically do have some wealth to protect, fail to buy LTC insurance, even when the chance they will spend down to Medicaid eligibility is low.

Adding to the puzzle is the fact that about 70 percent of the elderly $d o$ purchase private "Medigap" insurance to supplement coverage of the public Medicare program. Medicare furnishes coverage against hospital inpatient and outpatient costs, and against the cost of physician services. However, Medicare has deductibles for both inpatient and physician services cost, and imposes a 20 percent copayment for the latter. Finally, there are upper limits on the number of hospital days which will be covered by the public program. Despite Medigap loadings of up to fifty percent of premiums (probably higher than would prevail for nursing home coverage), the great majority of the elderly do buy private Medigap coverage against the uncovered portions of these acute care expenses.

One should be cautious, however, in interpreting this result as providing evidence on the degree of risk aversion among potential elderly nursing home insurance purchasers, for two reasons. First, a sizeable portion of the expenses Medicare does not cover does occur early in the course of illness, as deductibles or initial copayments. Thus Medigap probably provides coverage against costs associated with illness episodes from which the probability of recovery, and return to full consumption opportunities, is substantially greater than for the episodes of incapacitating chronic illness associated with nursing home care; the marginal utility of money may well be higher in the "well" state than in the "near death" state (Pauly [1988]). Second, in probable contrast to Long Term Care insurance, Medigap coverage is subsidized in the sense that its purchase induces (via moral hazard) a greater use of Medicare covered benefits for which no additional Medicare premium is charged. In contrast, the availability of LTC insurance may obviate the need for covered inpatient hospitalization; LTC coverage may well substitute for Medicare coverage.

A final noteworthy fact is that Medigap purchase has a strong positive relationship to income and wealth. Thus the families most likely to become eligible for Medicaid are not the families buying Medigap coverage.

\section{A model of insurance purchase decisions}

To simplify matters, I assume that moral hazard does not occur, either for public or private insurance. Private insurance coverage does not induce additional use, and public (Medicaid) coverage provides the same quality and access that would have been available under private coverage. I also assume that the individual does want to transfer resources to the "high cost illness" state; even if he does not go on Medicaid he is averse to this risk. ${ }^{1}$

\footnotetext{
${ }^{1}$ Some reasons why this may not always be a reasonable assumption are discussed in Pauly [1988].
} 
In this setting, the only consequence of the failure to obtain private coverage is a loss in wealth equal to the amount of the nursing home bill. A nursing home stay can be terminated either by recovery or death. For stays of more than 30 days, about 80 percent are terminated by death or hospitalization.

Let us begin with the simple case in which the individual faces three possible outcomes with regard to LTC expense X. He has

$$
\begin{aligned}
& P_{1}=1 / 2 \text { that } X=O \\
& P_{2}=1 / 4 \text { that } X=S<W \\
& P_{3}=1 / 4 \text { that } X=2 W
\end{aligned}
$$

where W is wealth. Medicaid pays in full for expenses in excess of W. Will the person buy insurance? It is easy to see that he will not buy insurance against event 3 , even if the insurance is offered at a fair premium. If he were to buy coverage I, he would pay .25I as a premium, but he would only buy protection in the amount of $.25(\mathrm{I}-\mathrm{W})$. To take an extreme case, if he sets $I \leqq W$, he pays .25I for the insurance, but has a zero wealth whether he buys coverage or not! The insurance therefore provides zero expected benefit. In general, even for $I>W$, it is as if there is a loading of $P_{3} W$; the individual may well choose to buy no coverage.

Perhaps, however, he will choose to buy coverage against event 2 , since event 2 does not reduce his wealth to zero. With no insurance, his wealth is reduced by $S$ if he becomes ill, but with full insurance his wealth would be $W-P_{2} S$, regardless of whether event 1 or event 2 occurs, if the insurance were offered at fair premiums. If the event itself could be specified in the insurance contract, a risk averse individual might well wish to buy coverage against event 2 , but not against event 3 .

Suppose, however, that insurance cannot distinguish types of illnesses or illness events, but instead must base benefits on the amount of loss. Coverage would still be purchased if policies were written on a "wait and see" basis. That is, the policy would have to say, "we will pay $\$ S$ if a loss of $\$ S$ occurs, but nothing if the loss exceeds $\$ S "$. The problem is that such a wait and see policy is certainly not typical of current private policies in the U.S., and may even violate Medicaid regulations.

If instead, the policy paid $\$ S$ regardless of what costs turned out to be, the person would have to pay a premium of $.5 \mathrm{~S}$ for coverage whose expected benefits are only half as great.

In this case, the person would buy coverage, even in the actuarially fair case, only if the risk premium he would be willing to pay to cover the loss of $\$ \mathrm{~S}$ was greater than $0.25 \mathrm{~S}$.

We can now generalize this example. Coverage may still be bought if event 3 is sufficiently rare. Formally, if $P_{W}$ is the probability that the loss exceeds the person's wealth, it is as if a loading of $P_{W} I$ is added to the fair premium for $\$ I$ worth of coverage, $I \leq W$. Especially if the fair premium is small, this can represent a substantial loading and can deter a risk averse person from purchasing coverage. 


\section{The case for a subsidy}

In this section I investigate when a subsidy to the purchase of long-term care insurance by the near poor would be warranted. We will define an "efficient" solution (somewhat restrictively) as one which actually does make both the elderly family and the taxpayers who pay for Medicaid better off. The maximum subsidy that would make taxpayers no worse off is $P_{3}(X-W)$, since this is what Medicaid pays in any case. If the elderly person is risk averse, he would be willing to pay $\Pi_{3}$, an amount greater than $P_{3} W$, for coverage against event 3 . Let us assume that he does not voluntarily buy coverage, so that $\Pi_{3}$ is less than $P_{3} X$. Let us also assume that the actual subsidy needed to cover costs, or $P_{3} X-\Pi_{3}$, is less than $P_{3}(X-W)$, the maximum subsidy taxpayers would be willing to pay; payment of a subsidy then makes other taxpayers compared to Medicaid. And charging $\Pi_{3}$, or a little less, makes recipients better off.

We can go further than this. Suppose the absence of "wait and see" policies means that the person also does not buy coverage against event 2 , even though $\Pi_{2}>P_{2} S$. It follows that the subsidy need only be $P_{3}(2 W)-\Pi_{3}+P_{2} S-\Pi_{2}$. That is, as compared to the subsidy that would have to be paid in the absence of insurance coverage, the offering of a subsidized policy would induce the individual to make a contribution equal to his risk premium for both event 3 and event 2 . Taxpayers will gain if the subsidy is less than $P_{3}(X-W)$. So long as the administrative cost associated with insurance coverage for event 2 does not exceed the person's valuation of insurance, it will be desirable to offer this "full coverage" insurance. The obvious implication of this model is that the optimal subsidy will tend to be higher for low wealth people, both because $P_{3}(X-W)$ will be greater for them, and because their willingness to pay for reduced risk is probably less.

In the model thus far, the only feasible insurance policy is full coverage. But any purchase of any coverage by the individual benefits taxpayers, as long as it is not "wait and see" coverage. Roughly speaking, the subsidy rate should be proportional to $P_{3} /\left(P_{2}+P_{3}\right)$, and therefore should depend both on wealth and on the probability density function for losses.

This argument implies not only that there should be a subsidy to those with incomes near the Medicaid limit, but that such a subsidy should be extended as far up the income distribution as (1) there is a positive expected value of Medicaid payments and (2) such a subsidy will induce the purchase of insurance. It remains the case that a subsidy may improve welfare even if the definition of "needy" is limited to incomes as low as would make the person eligible for Medicaid.

Of course, the subsidy may not be effective in inducing purchases, but there is no reason not to offer a subsidy less than $P_{3}(X-W)$. The subsidy is costless unless it is accepted, and acceptance makes both recipients and taxpayers better off.

\section{Welfare effects}

How do the welfare effects of this subsidized coverage model compare with those of conventional Medicaid? The critical point is that there is the possibility of a Pareto optimal move. Because the subsidy can be more than the minimum amount needed to induce the purchase of coverage, elderly subsidy recipients can gain. But because taxes paid for the subsidy can be less than the Medicaid cost, taxpayers gain as well. 
Elderly beneficiaries gain in two ways. They get insurance coverage against the risk of uncertain expenses (and uncertain bequests), which may be of some value. Moreover, even though they receive no additional benefits when SX exceeds $\mathrm{W}$, they get a benefit in the sense that they avoid the "stigma of impoverishment". In effect, an amount equal to $P_{3} W$ is confiscated from the elderly, but it is spread over all elderly, not taken as a cost of $\$ W$ on some fraction $P_{3}$ of the elderly. Each elderly person is now left with wealth $W-P_{3} W$, whereas before the fraction $\left(1-P_{3}\right)$ was left with wealth $W$ and the fraction $P_{3}$ was left with zero wealth. This may well represent an improvement in wellfare.

These welfare effects concentrate only on money as a source of well-being. It is frequently alleged that the greatest tragedy of long-term care financing in the United States is not the risk imposed on the elderly or their heirs. It is instead the "stigma of impoverishment", for people who felt reasonable self-sufficient all their lives. Turning to the Medicaid program, with its connotation of welfare for poor people, is thought shameful by many of the elderly.

The plan just outlined avoids this threat to self-respect. Every individual becomes fully insured, so that there is no threat of health-care-cost induced bankruptcy. Representing one's wealth as being low for purposes of receiving a greater subsidy would not, one presumes, be regarded as a stigma, just as representing one's income as low for purposes of paying lower taxes is not regarded as shameful.

There is, in any case, no obvious reason why one should label the fact of becoming eligible for Medicaid nursing home benefits as "impoverishment". An individual with a middle class pension income, and modest financial wealth will become eligible for Medicaid after the financial wealth is consumed in a nursing home stay. The pension income must then be used to pay for nursing home care, with only a small allowance for personal needs permitted. But is it appropriate to label this individual as "impoverished"? Where the patient to recover and leave the nursing home, he or she would return to a middle class income; only the financial assets, which are often quite small, are lost. It is sometimes said that going on Medicaid requires depletion of the "savings of a lifetime", but this is incorrect. For most people, the great bulk of their saving activities are tied up in annuities and pensions, public and private; these savings are not depleted. Thus in a meaningful sense people are not impoverished when they become eligible for Medicaid. Their financial wealth is slightly eroded, but the present value of their expected lifetime future consumption stream - which is, after all, the proper economic definition of wealth - remains for most middle class people at the middle class level.

\section{Heterogeneous consumers}

If individuals differ in terms of risk aversion, it will obviously not be possible to tailor the subsidy perfectly to each individual's demand for insurance. Ordinarily, heterogeneity threatens to make subsidies inefficient from the taxpayer's viewpoint, since some of the subsidy is "wasted" on people who would have made the desired purchase in any case. But with such a small level of private insurance coverage, this is not really a threat. The only risk is that, for any subsidy short of $P_{3} W$, some persons with very low risk aversion may choose not to buy insurance. But then they still cost taxpayers a per-person amount equal to $P_{3} W$, since they in effect go back to "old" Medicaid. But for those persons who do accept the subsidy and purchase insurance, there is a gain. 


\section{Other considerations}

This argument implies that there is a case for a subsidy to private LTC insurance, a subsidy that varies inversely with income and equals, at its maximum, the expected value of Medicaid payments for each income level. Current policy proposals in the U.S. appear, however, to involve subsidies to higher income populations in larger amounts than would represent expected Medicaid payments. The primary vehicle for offering such subsidies is through various tax provisions, provisions which permit people to shield contributions toward insurance premiums (or employer contributions on their behalf) from taxation. Such subsidies would, of course, vary directly with the marginal tax rate. Are there any welfare economic rationales for such subsidies?

Loading costs for private LTC insurance clearly could discourage purchasing. But loading costs for this type of insurance probably would not exceed those for other insurance (life or property/casualty) for which individual insurance is frequently purchased. While these comparisons are not conclusive, they do suggest that loading costs alone cannot help to explain the absence of a market. As long as the private market for LTC insurance is still to be used, there is likewise no case for public subsidization. There could be a case for public production of LTC insurance, if public sector activities reduced the administrative cost of such isurance. This public production could either be in the form of direct and exclusive public production, or in the form of public efforts to act as a middleman (Friedman and Manheim [1988]).

Adverse selection in LTC insurance is also clearly a possibility, especially if the individual can buy coverage that becomes effective immediately and if preexisting condition exclusions are difficult to enforce. There are partial solutions possible - limiting coverage, requiring payment of premiums well in advance of eligibility (even to the extent of accumulating a fund during one's working lifetime), or excluding preexisting conditions. But there is no doubt that adverse selection can prevent the emergence of a market, especially if the loading is high and there is a non-trivial fraction of persons with high probabilities of loss who cannot be excluded from coverage.

Subsidizing premiums may be efficiency-improving when adverse selection is present, as may a social insurance approach. However, it is also possible that there is no Pareto superior alternative to an equilibrium with zero insurance. Suppose some people have probabilities so high that, when loading is added, the premium exceeds the level of benefits. Then these high risks will not buy coverage in any type of separating equilibrium, permanent or temporary. And there will be no way to tax lower risks to make everyone better off. That is, if the market is characterized by an equilibrium with zero coverage, there is no way to design cross-subsidies which lead to Pareto moves as long as all insurances have the same loading costs.

\section{Externalities and subsidies}

As an alternative to these arguments, we might imagine that the major rationale for public interest in LTC is one based on altruistic externalities (Pauly [1970]): the notion is that, without insurance, some individuals may consume levels of LTC so low that others would benefit subjectively from (be willing to pay something for) additional insurance coverage or additional care for that person. It is presumably this rationale that helps to 
explain why the Medicaid program exists. The question here is whether additional subsidies, beyond the Medicaid-based subsidies described above, ought to be paid. Should any population group receive a subsidy larger than the expected value of their Medicaid payments?

In principle, the answer to this question could be positive: externalities are not necessarily exhausted at the level represented by current levels of Medicaid payments. But in practice, there is an important institutional fact which limits the case for further subsidization, especially subsidization intended to make it possible for more people to obtain nursing home placement. In most states in the U.S., there is an excess demand for nursing home beds, caused by the requirement that a home receive a Certificate of Need from a government agency before it may legally offer beds to the public. Empty beds are uncommon, and use of a bed by one person means that another cannot receive care. High income people who pay privately for beds can usually obtain them, but there is widely thought to be a shortage of beds for Medicaid beneficiaries.

In this setting, a subsidy or public program to LTC insurance which increased the private demand for beds (e.g., the tax subsidy to long term care proposed by Bowen and Burke [1985]) would only result in upward pressure on nursing home prices and a reallocation of beds away from poor Medicaid beneficiaries. With a fixed stock of beds, externalities cannot be reduced by caring for more people. There is only the possibility of reallocating beds, and it would seem that removing Medicaid beneficiaries from beds would probably not improve matters. If the bed constraint is non-biding, or if non-nursing home formal care is available, then public subsidized LTC insurance can in theory do some good. But we can say little more without some quantification of the benefits to be achieved by greater coverage or formal care, and of the value taxpayers place on those benefits.

\section{Conclusion}

The United States currently provides public payments for about half of all nursing home care. It should be possible to provide that subsidy more effectively, by linking its payment to the purchase of genuine insurance. That insurance could either be publically and privately produced, but, in any event, should be offered as an alternative to Medicaid. All that is required is an ability to calculate the average Medicaid payment by initial wealth class.

\section{REFERENCES}

BOWEN, O. R. and BURKE, T. R. [1985]: "Cost neutral catastrophic care proposed for medicare recipients", FAH Review, 18 (November/December 1985), 42-45.

FRIEDMAN, B. and MANHEIM, L. [1986]: "Should medicare provide expanded coverage for long term care?", paper presented at Conference on the Next Twenty Years of Medicare, University of Pennsylvania, October 1986.

PAULY, M. [1970]: Medical Care at Public Expense, New York: Praeger Publishers.

PAULY, M. [1988]: "Rational nonpurchase of nursing home insurance", Leonard Davis Institute of Health Economics, University of Pennsylvania, January 1988. 